\title{
Interdisciplinary Education of Foreign Language Majors in Chinese Local Universities under the Background of New Liberal Arts
}

\author{
Jianshan Cheng ${ }^{1}$ \\ ${ }^{1}$ School of Foreign Languages, Wuhan Institute of Technology, Wuhan, Hubei, China \\ Correspondence: Jianshan Cheng, School of Foreign Languages, Wuhan Institute of Technology, Wuhan, Hubei, \\ 430205, China.
}

Received: January 27, 2022

Accepted: February 20, 2022

Online Published: February 25, 2022

doi: $10.5539 /$ elt.v15n3p38

URL: https://doi.org/10.5539/elt.v15n3p38

\begin{abstract}
New liberal arts refer to the reorganization of traditional liberal arts to realize the intersection and integration within liberal arts and between liberal arts and natural sciences. The characteristics of new liberal arts are mainly problem-orientation, cross-integration, new technology application and innovative development. Under the background of new liberal arts, the implementation of interdisciplinary education in foreign language majors is an effective way for local colleges and universities to promote the construction of "new foreign languages" and the training of interdisciplinary and applied foreign language talents. Based on the connotations of new liberal arts and interdisciplinary education, and in view of the institutional and cultural barriers to the planning and implementation of interdisciplinary education, this paper proposes an optimized path for the design and implementation of interdisciplinary education for foreign language majors in local colleges and universities: deepen the integration between foreign language majors and other disciplines, build a staged, multi-level talent training system, set up cross-discipline curricular groups, apply new technology to transform traditional teaching and learning methods, strengthen the construction of interdisciplinary education platforms and faculties, and establish a foreign language interdisciplinary education system guarantee mechanism.
\end{abstract}

Keywords: new liberal arts, local colleges and universities, foreign language majors, interdisciplinary education

\section{Introduction}

The current world situation has undergone tremendous changes. With the advent of the era of globalization, networking, and intellectualization, the field of higher education has ushered in new opportunities and challenges In 2017, the concept of "New Liberal Arts" was born in Hiram College in the United States. Its connotation is to reorganize traditional liberal arts, emphasize the intersection of liberal arts and sciences, and integrate new technologies into traditional humanity courses such as philosophy, literature, and language, so as to provide students with comprehensive and interdisciplinary learning and research opportunities. (Wang, 2019) "New Liberal Arts" in China was launched by the "Opinions on Accelerating the Construction of High-Level Undergraduate Education and Comprehensively Improving the Ability of Talent Training" issued by the Ministry of Education in October 2018, in which the overall deployment of the construction of new engineering, new medicine, new agricultural science, and new liberal arts was put forward. The "Four News" has thus become a hot topic in higher education circles. On November 3, 2020, the Ministry of Education held a kick-off meeting to fully promote the construction of new liberal arts at Shandong University. At the meeting, the "New Liberal Arts Construction Declaration" of Chinese universities was released, which pushed the construction of new liberal arts to a climax. On March 2, 2021, the Ministry of Education issued the "Notice on Recommending New Liberal Arts Research and Reform Practice Projects" (Correspondence of Bureau of Higher Education [2021] No. $10)$, in which the Ministry of Education decided to launch the practice projects of new liberal arts research and reform. It is worth noting that in the more than two years of the rise of new liberal arts, foreign language majors have been at the forefront of reforms.

In recent years, as the employment of foreign language graduates in local colleges and universities in China is deteriorating, foreign language majors in some local colleges and universities are facing cancellation, and the foreign language education community is increasingly calling for the transformation of foreign language education and talent training. The foreign language discipline system in local colleges and universities is relatively simple, lacking diversification, specialization and interdisciplinarity; the curriculum is outdated 
without clear characteristics and the knowledge structure of students is relatively scattered, which cannot fully adapt to the internationalization of education and demand for interdisciplinary and applied foreign language talents of the national "Belt and Road" initiative. It is even more stretched to meet the challenges of foreign language training model and teaching methods brought by information technology and artificial intelligence. These problems show that foreign language education in local colleges and universities must actively seek changes, make the top-level design of interdisciplinary education, develop interdisciplinary foreign language majors, promote the integration and intersection of foreign language and other disciplines, and create an interdisciplinary curriculum system and teaching model to cultivate professional interdisciplinary foreign language talents suitable for the needs of local social development. This paper will review the origin, connotations and characteristics of new liberal arts, discuss the construction of foreign language discipline under the context of new liberal arts and the difficulties in the design and implementation of interdisciplinary education for foreign language majors and it will propose an optimized path to plan and effectively implement interdisciplinary education suitable for the development positioning and actual conditions in local colleges and universities.

\section{Literature Review}

In 2017, Hiram College first proposed the concept of "new liberal arts", which they explained were mainly about integrated major and interdisciplinary education. (Lori Varlotta, 2018) Students of different majors broke the boundaries of professional courses for comprehensive interdisciplinary learning. There are many similar expressions, but breaking professional boundaries to conduct interdisciplinary learning is not new. As early as 1926, the term "interdisciplinary" firstly appeared in the United States. With the continuous strengthening of the integration of academic research, "interdisciplinary" has received more and more attention from academic circles. The first International Symposium on Interdisciplinary Issues was held in France in 1970. In 1976, the first international interdisciplinary academic journal "Interdisciplinary Science Review" was published. China also began to attach importance to interdisciplinary issues in the 1980s. In 1985, the first national interdisciplinary academic symposium was held. In the same year, the magazine "Future and Development" published a paper entitled "Interdisciplinary Science" in the first issue. (Huang \& Tian, 2020) As far as China's "new liberal arts" is concerned, it is not only limited to program reorganization and cross-disciplines, but also has many new features, such as emphasizing Chinese characteristics and going to the center of the world stage.

Since the construction of new liberal arts was proposed, many scholars have focused on the research objects, disciplinary attributes, and basic characteristics of new liberal arts and made a series of critical researches and interpretations, among which "innovative theory" and "integrative theory" are the most representative. (Ma, Li, $\&$ Sun, 2021) The "innovative theory" believes that "the core of new liberal arts is innovative against traditional rather than new against old." It emphasizes the epochal character of new liberal arts, which is examined and understood under the big context of constructing philosophy and social sciences with Chinese characteristics. The "integrative theory" emphasizes the compatibility of new liberal arts. Xu (2019) claims that "new liberal arts will connect liberal arts and sciences, humanities and social sciences, China and West, and knowledge and practice." Chen (2019) argues that the mobile Internet has completely changed the production method and lifestyle of mankind, so unprecedented legal, ethical and moral problems have emerged. To solve these problems, it is clear that a single discipline cannot be relied on, and multidisciplinary collaboration is necessary. In his view, new liberal arts is precisely based on the internal integration of liberal arts and the intersection of arts and sciences to research, understand and solve the complex problems of the discipline itself, people and society. Fan (2020) explained the "new" connotations of new liberal arts from four dimensions: "the integration of new technological revolution and liberal arts, entering a new era and sinicization of liberal arts, new historical timeline and new missions of liberal arts, new global pattern and internationalization of liberal arts". These scholars' research and interpretation on the connotations and characteristics of new liberal arts emphasizes the compatibility, innovation and epochal character of new liberal arts on different levels, which will help us deepen our understanding of new liberal arts.

The implementation of new liberal arts aims to break the barriers between traditional liberal arts and other disciplines, and its characteristics are mainly manifested as problem-orientation, cross-integration, new technology application and innovative development. (Hu, 2020) (1) Problem-orientation. New liberal arts has been problem-oriented since its inception. With the rapid development of human society, many new phenomena and problems have emerged one after another. The interpretation of these phenomena and the solutions to problems are often difficult to achieve by relying on the "single-soldier combat" of traditional liberal arts. Only by achieving the intersection and integration between liberal arts and other disciplines can we conduct effective research on these phenomena and problems. Moreover, due to the complexity of the world and the limitations of 
human cognitive ability, the boundaries between disciplines are constantly being broken, and the interdisciplinary trend is inevitable. In fact, the development history of modern science has shown that major scientific advances or the emergence of new disciplines are often the results of different disciplines intersecting and infiltrating each other. In this sense, the emergence of new liberal arts is based on the need to explain new phenomena and solve new problems, and it is also the inevitable development of contemporary academic research. (2) Intersection and integration. Compared with traditional liberal arts, the most significant feature of new liberal arts is undoubtedly the intersection and integration between disciplines. New liberal arts are based on liberal arts and at the same time emphasize the intersection and integration not only within humanities and social sciences, but also between humanities and social sciences and natural sciences, that is, the intersection of arts and sciences, arts and medicine, and arts and engineering. In the United States, many colleges and universities attach importance to STEM (Science, Technology, Engineering and Mathematics) education focusing on cultivating students' literacy in science, technology, engineering and mathematics. Later, it involves arts subjects such as social studies, language, physique, music, aesthetics, and performance so that STEM has gradually evolved into STEAM in order to cultivate the innovative ability and critical thinking of science and engineering students. This measure shows that in terms of talent training, new liberal arts can break through the limitations of humanities and social sciences, and integrate a wider range of disciplines and majors within the scope of arts and sciences, and arts and engineering, so as to promote the overall improvement of students' quality and abilities. (3) New technology application. New technology refers to the high-tech fields represented by information technology that have emerged in the 21 st century. Information technology mainly refers to the acquisition, transmission, and processing of information, including new foundations represented by quantum computing, 5G and AI chips, new intelligence represented by online computing, big data processing and large-scale machine learning, and machine intelligence, unmanned driving, and typical new applications represented by intelligent networking and block chain. These new technologies, especially information technology, are gradually being applied to the humanities and social sciences, which can not only change the research paradigms but also the major fields of humanities and social sciences. On the one hand, due to the application of digital technology, researchers of humanities and social sciences can discover and reveal new problems through data collection, analysis and mining, and then apply and develop corresponding theories based on data and facts. Moreover, the digitization of research literature and its network sharing model have broken the closed research model of humanities and social sciences, and led to an open and shared collaborative research and learning model. On the other hand, the application of new technologies in humanities and social sciences provides a technological path for the intersection of data science, cognitive neuroscience, computing science and humanities and social sciences, and thus has created new research fields for humanities and social sciences, such as social computing, financial technology, spatial econometrics, philosophy of technology and computational linguistics. (4) Innovative development. New liberal arts emphasizes the goal of innovative development through the integration of disciplines. Its innovative development is mainly manifested in four aspects: (1) New context. New liberal arts attaches great importance to the historical context of the rapid development of global new technologies and the new stage of the development of socialism with Chinese characteristics. (2) New ideas. New liberal arts emphasizes that the construction and development of humanities and social sciences should shift from subject-orientation to problem-orientation, and advocates the intersection and integration between humanities and other disciplines to promote the upgrading of traditional liberal arts. (3) New content. The curriculum design and content and research fields of new liberal arts are different from those of traditional liberal arts, and they present significant features of intersection and integration. (4) New paradigm. New liberal arts advocates the development of interdisciplinary research, especially the cross-integration research between humanities and other disciplines to cultivate interdisciplinary talents.

\section{New Liberal Arts and Construction of Foreign Language Discipline}

The discipline of foreign languages is an important force in advancing the internationalization of Chinese humanities and ushering the trend of international frontier academics. The surging tide of new liberal arts construction has put forward new goals and requirements for the reform and development of foreign language education, and has also created new conditions and opportunities. It's an urgent need to use strategic and innovative thinking to improve the training model and the connotative development of foreign language discipline under the guidance of new liberal arts, so that it can play an important role in the construction of new liberal arts. (Wang, 2021) Then, what does new liberal arts mean for foreign language discipline?

First, New liberal arts highlights "new". In this context, foreign language majors need to find a new position in order to achieve new changes and breakthroughs. The "National Standards for the Teaching Quality of Foreign Languages and Literature" (hereinafter referred to as the "National Standards") clearly pointed out that foreign 
language majors are an important part of humanities and social sciences in China's higher education. In view of the relatively weak position in liberal arts, foreign language majors urgently need to be de-marginalized to improve their status and position in the construction of new liberal arts and enhance their sense of identity. Foreign language majors should align with and participate in the "Strong Foundation Project" (Note 1) through intersection and integration, actively benchmark the "Six Excellence and One Top-notch" plan 2.0 (Note 2) to create a new brand of "excellent foreign language talents", and establish a new image of foreign language education that integrates and unifies humanity, instrumentality and scientificity.

Second, new liberal arts emphasizes "cross-discipline". In this context, foreign language majors should actively take the road of cross-languages, cross-majors, and cross-disciplines, reflecting the interdisciplinary characteristics clearly defined in the "National Standards". New liberal arts attaches importance to the integrative development between liberal arts and sciences, emphasizing the integration between arts and arts, arts and sciences, arts and medicine, and arts and agriculture. Foreign language majors have the characteristics of universality, inclusiveness and openness. Through intersection between foreign language majors, multilingual, high-end foreign language talents such as multilingual translators can be cultivated; through crossover with other majors, interdisciplinary talents with different combinations of "foreign language + " and "+ foreign languages" can be cultivated.

Third, new liberal arts adheres to "arts". In this context, foreign language majors should stick to their own discipline and professional characteristics. "New foreign languages" under the background of new liberal arts should strengthen and highlight the essence of "arts" and insist on the characteristics of "foreign languages". Foreign language majors are not only concerned with learning (the skills of) foreign languages, but it also needs to implement a comprehensive reform of humanities, continuously empowering content, and enhancing the additional value of "arts". (Zha, 2017) What needs to be pointed out is that the integration of foreign language majors with other majors is not simply superimposition, let alone randomly scrabbling up. It's based on all-round development of students, highlighting the individualized development of foreign languages. "Foreign languages +" can strengthen the solid foundation of foreign language skills, highlighting humanities and enhancing professional core competitiveness; "+ Foreign Languages" is to enrich the connotation, expand the professional interface, and enhance the attractiveness and absorption of other disciplines. Only by holding on to the dominant role without being a vassal can foreign language majors make new achievements and attain new status.

Fourth, new liberal arts highlights "China" characteristics. In this context, foreign language majors should play an active role in constructing the discourse system of philosophy and social sciences with Chinese characteristics. Only with the renewal of ideas, the construction of theories, the innovation of methods and the transformation of paradigms can we promote academic openness and inclusiveness and enhance the power of international academic discourse. To this end, foreign language majors should enhance the awareness and identity of "big liberal arts" and take the initiative to integrate with other majors. By strengthening the construction of "big foreign languages", we can achieve cross-disciplinary breakthroughs and contribute to the formation of guiding ideology, discipline system, academic system, and discourse system with Chinese characteristics. Breathing with the times and sharing the fate of China, foreign language majors can play an indispensable role in the construction of new liberal arts.

\section{Difficulties in the Design and Implementation of Interdisciplinary Education for Foreign Language Majors in Local Colleges and Universities under the Background of New Liberal Arts}

Under the background of new liberal arts, the external logical starting point and basis of interdisciplinary education of foreign language majors in local colleges and universities have gradually been recognized and accepted by people, but there is still a lack of in-depth exploration of the design and planning at the internal operational level. Only a thorough understanding of the current difficulties and problems of interdisciplinary education in local universities can make foreign language interdisciplinary education truly effective at the practical level.

1) Management and resource allocation. The characteristics of interdisciplinary education are blurred discipline boundaries, scattered educational forms, and multi-directional participation of personnel. (Qiu, 2004) Interdisciplinary education of foreign languages is dominated by foreign language discipline but intersected, penetrated and integrated with other similar disciplines. In the form of educational organization, foreign language and other disciplines need to cooperate in personnel training, resource allocation and management. However, under the current Chinese university system, the barriers between disciplines and majors are tight and the boundaries of educational resource ownership are clear. This discipline management system greatly hinders the participation of teachers of non-foreign language disciplines in 
interdisciplinary foreign language teaching. Additionally, other factors such as the interest competition among cooperators have also led to low efficiency in the practical operation of foreign language interdisciplinary education, and it is difficult to truly integrate all aspects. (Wang, 2018)

2) Talent training mechanism. Regarding the foreign language interdisciplinary talent training mechanism, many local colleges and universities have adjusted their major setup and talent training objectives in the transformation to application-oriented universities, and shifted to the interdisciplinary education and talent training model of "English + major". However, this kind of interdisciplinary foreign language major has caused continuous disagreements and controversies in the foreign language education community since its birth due to its "inherent deficiency of disciplinary foundation and unclear disciplinary orientation". (Zhang \& Chen, 2011) For example, researchers pointed out that in terms of educational content and talent training mechanism, most local universities have not dug deep into the connotations of foreign language interdisciplinary education due to the lack of qualified interdisciplinary faculties, so that the training of compound foreign language talents has become superficial, mechanized, and simplified. (Wang, 2018) One of the typical phenomena is that, at present, the implementation of multidisciplinary foreign language talent training programs in many local universities is jointly responsible by foreign language teachers and non-foreign language teachers by setting up language knowledge modules and professional knowledge modules respectively. (Jiang, 2018) This kind of curriculum and talent training mechanism seems to present knowledge of different subjects in a variety of curriculum modules, but the lack of multidisciplinary integration and overall planning and coordination between different curriculum modules has always placed the cultivation of talents in local colleges and universities in the situation of "double skins", and it is difficult to achieve the goal of interdisciplinary education.

3) Discipline culture mechanism and university education paradigm. Discipline culture is "produced by the development of a discipline to a certain extent, and it is a general term for various linguistic symbols, theoretical methods, value standards, ethical norms, and ways of thinking and behavior created by scholars in a certain period of time based on disciplines". (Jiang, 2007) Practical differences in theoretical perspectives, thinking methods, and research paradigms in different disciplines have led to the differences in educational research paradigms between different disciplines. The effective implementation of foreign language interdisciplinary education requires teachers from different discipline culture backgrounds and educational research paradigms to form a unique discipline structure through the exploration of interdisciplinary talent training objectives, training models, teaching content and educational methods. The conflict between the intrinsic needs of foreign language interdisciplinary education and the unique and exclusive characteristics of different discipline cultures and educational paradigms has posed internal obstacles for the design of foreign language interdisciplinary education.

4) Realistic basis of foreign language interdisciplinary education. Interdisciplinary education and research have widely spread in education community after China held the "Interdisciplinary Science Conference" in the 1980s. The proposal of new liberal arts construction has further strengthened the important position of interdisciplinary education in the field of higher education. At present, many key universities in China have made remarkable achievements in interdisciplinary education, but local colleges and universities are relatively lagging behind, because the research and practice foundation for the interdisciplinary education of foreign language majors in local universities is very weak. For example, there are few foreign language teachers who have engaged in interdisciplinary education and teaching research, so their interdisciplinary teaching ability is insufficient, and the scope of interdisciplinary cooperation research is relatively narrow. Most of them cooperate with teachers majoring in humanities and social sciences, and the depth and breadth of interdisciplinary research are still at a low level. In addition, many local colleges and universities have insufficient interdisciplinary research conditions, and teachers lack standardized interdisciplinary training and research. (Sun, 2018)

5. Optimized Path for the Design and Implementation of Interdisciplinary Education for Foreign Language Majors in Chinese Local Universities under the Background of New Liberal Arts

a) Follow the basic rules of inter-disciplines and elevate the degree of integration between foreign languages and other disciplines. Cross-discipline is the product of the development of modern science and technology, which has its own connotative characteristics and basic laws of implementation. Li (2017) concluded that true cross-discipline aims at solving practical problems, relying on the related disciplines of complex problems to promote the emergence of new cognition based on integrated research thinking. For the interdisciplinary foreign language education in local colleges and universities, whether it is helpful to cultivate interdisciplinary and applied foreign language talents in line with regional economic development 
is the starting point for considering the choice of inter-disciplines. On the basis of this starting point, it is the basic prerequisite for the implementation of interdisciplinary foreign language education to integrate research paradigms, educational theories and methods of different disciplines so as to update the concept of traditional foreign language education and enrich educational methods and means of interdisciplinary foreign languages.

b) Focus on the training goals of interdisciplinary and applied foreign language talents, and build a staged, multilevel talent training system. The core of education lies in the cultivation of talents. The interdisciplinary education of foreign language majors in local colleges and universities needs to put the training of talents that meet the needs of the new era and new liberal arts construction at the core, and use this as the cornerstone to radiate the deepening reform of the entire talent training system. Therefore, in the implementation strategy, we should first clarify the goal of talent training. The cultivation of interdisciplinary and applied foreign language talents is the main focus of the current design and implementation of foreign language interdisciplinary education in local colleges and universities. "Interdisciplinary" is the method and means of foreign language talent training; "compound" emphasizes that foreign language interdisciplinary education must cultivate talents with integrated knowledge, abilities, and comprehensive literacy; "applied" highlights the practical ability of students to use multidisciplinary knowledge and skills to solve complex social problems. The three goals are organically combined and unified into a whole. Secondly, in terms of implementation actions, a "three stage and three level" talent training system can be constructed. The first stage is the "basic integration" period. In this stage, local colleges and universities offer general humanities and business courses, enabling students to experience the initial combination of professional learning. The second stage is the "extended integration" period. In this stage, local colleges and universities consciously build talent training platforms, such as interdisciplinary compound foreign language talent experimental classes, and interdisciplinary foreign language cooperation project research groups, etc., so that students can receive professional training. The third stage is the "comprehensive integration" period. On the basis of the first two stages, all disciplines and professional barriers in the university are broken up to meet the diverse development needs of students to encourage the integration of foreign languages with other characteristic disciplines and improve their professional practice capabilities through the "major-dual-minor" training program by focusing on training students' knowledge and skills at the professional level. In addition, the interdisciplinary compound talent training system of foreign languages in local colleges and universities can also expand from a single interdisciplinary integration within the university to a multifaceted intercollegiate and international joint training to deepen the connotation of foreign language interdisciplinary education and talent training.

c) Establish an interdisciplinary curricular group to strengthen the comprehensive and interdisciplinary characteristics of the professional teaching system. Foreign language interdisciplinary education is a new educational paradigm developed in the field of foreign language discipline. It mainly appeals for breakthroughs in integration of education and teaching design and emphasizes the value concept of education from singularity to pluralism and complexity. (Sun 2012) For local colleges and universities, this diversified and compound education concept aims at cultivating interdisciplinary and applied foreign language talents, which is achieved through the integration and innovation of teaching, and optimizing the curriculum system is the key to the integration of professional teaching. On the basis of the above "three-stage, three-level" talent training system, interdisciplinary curricular groups suitable for different stages and levels can be divided into the following three categories: (1) general education curriculum group, mainly basic courses of foreign languages and general humanities, such as political history, economics and management, comprehensive science and technology, art and sports, focusing on establishing a generous knowledge structure for students in the lower grades to provide them initial interdisciplinary learning experience. (2) infiltrating interdisciplinary curriculum group, formed through the integration of courses of foreign language majors and professional courses of relevant disciplines, which mainly includes interdisciplinary professional basic courses and main courses, enabling students to learn basic knowledge and skills in interdisciplinary professional fields. (3) professional cross-discipline curriculum group, which are professional core courses based on the first two levels of curriculum group, the individual needs and choices of students, including interdisciplinary foreign language practice courses and personality development courses, with the purpose of improving students' professional and comprehensive literacy simultaneously. The formation of the three types of cross-discipline curricular groups provides a dynamic and orderly system guarantee for the all-round development of students, and ensures the effective implementation of the interdisciplinary teaching system for foreign language majors. 
d) Transform traditional teaching and learning methods, and give play to the innovative role of new technology in interdisciplinary education. The adjustment of foreign language interdisciplinary education to the traditional foreign language education structure, talent training objectives and curriculum system has prompted changes in teaching and learning methods, forming a new interdisciplinary teaching method. (Lai \& Mao, 2009) The introduction of cutting-edge technologies such as information technology, big data and artificial intelligence can help the implementation of interdisciplinary foreign language teaching methods, promote the transformation of teaching and learning methods, and provide convenience for the realization of in-depth and highly integrated interdisciplinary learning conditions. In the context of interdisciplinary education, teachers' professional literacy, knowledge, and ability measurement standards have changed. Teachers should have the ability to update knowledge, expand cross-disciplines, and use information and artificial intelligence technology for education and teaching, so as to adapt to the interdisciplinary teaching pattern. The application of modern educational technologies such as artificial intelligence lays the foundation for teachers' multidisciplinary knowledge reserve and comprehensive skill reserve. Under interdisciplinary teaching methods, students' learning styles have changed from passive learning to autonomous learning, from unitary knowledge learning to multiple knowledge learning, and from linear learning space to three-dimensional learning space. $(\mathrm{Li}, 2012)$ With the help of new technologies such as artificial intelligence, through informational teaching methods such as "smart teaching", online and offline hybrid learning, mobile learning, virtual situational learning, etc., students are given fuller initiative and creativity to improve the integrity, selectivity and effectiveness of students' grasp of knowledge. Therefore, from the background of the times, integrating new technologies to transform traditional teaching and learning methods is an important way to promote foreign language interdisciplinary education.

e) Strengthen the construction of interdisciplinary education platforms and faculties, and provide practical organization and personnel guarantee. The interdisciplinary education of foreign language majors needs to make breakthroughs in the construction of interdisciplinary education platforms, the sharing of interdisciplinary education resources, and the construction of interdisciplinary teaching staff. To this end, local colleges and universities must first reform their internal organizational structure based on the needs of interdisciplinary foreign language talent training, integrate foreign languages and related interdisciplinary educational resources, and build a variety of flexible interdisciplinary educational platforms, such as interdisciplinary featured classes, project-oriented interdisciplinary study groups, research groups of foreign language interdisciplinary courses and teaching materials, and interdisciplinary teaching and training teams. The interdisciplinary education of foreign language majors in local colleges and universities also needs a team of teachers who are familiar with foreign language education and other subject knowledge and have interdisciplinary qualities to promote the scientificization of foreign language interdisciplinary education. Local colleges and universities can explore ways to build interdisciplinary faculty from the following aspects. First, broaden the development channels of foreign language teachers and create conditions for training and learning at home and abroad, inside and outside the university. Second, optimize the structure of teachers and supplement the foreign language interdisciplinary teaching team with high-level professional talents with outstanding English proficiency, solid professional knowledge, and strong practical ability in various industries. Third, enhance the training of "dual-professional" teachers and encourage foreign language teachers to cooperate with social enterprises and carry out teaching and scientific research. Fourth, reform the teacher evaluation mechanism, improve the reward system, and give policy preference to interdisciplinary foreign language teachers in terms of professional title promotion, salary level evaluation, and selection of excellent teachers.

f) Establish a foreign language interdisciplinary education system guarantee mechanism to promote management innovation. In view of the scattered forms of interdisciplinary education and the multi-directional participation of personnel, foreign language interdisciplinary education should first establish an interdisciplinary curriculum teaching form as an entry point and focus on the training objectives of interdisciplinary foreign language talents. Secondly, in terms of the structure of the education system, local colleges and universities can explore the creation of an orientative and open guarantee system based on the development of interdisciplinary education concepts and practices and implement the chief professor responsibility system. In addition, the management level should be downplayed in the management organization structure, and flat and collaborative management should be implemented instead. Moreover, it is necessary to promote the construction of a foreign language interdisciplinary education base and connect the university with social institutions to improve the industrialization process of interdisciplinary education. 


\section{Concluding Remarks}

New liberal arts refers to the disciplinary reorganization of traditional liberal arts to realize the integration between liberal arts and natural sciences. New liberal arts emphasizes the cultivation of interdisciplinary talents and conducts interdisciplinary research within liberal arts and between liberal arts and other disciplines. Yang (2019) pointed out that the interdisciplinary spirit reconstructed the connotative structure of foreign language discipline, dispelled the internal weakness of the discipline and made foreign language education resourceful and proficient. In short, the concept of new liberal arts has endowed foreign language education with an interdisciplinary temperament. For this reason, the foreign language disciplines in local colleges and universities under new liberal arts background should be based on foreign language disciplines, focus on cultivating compound foreign language professionals with a knowledge structure that achieves the intersection of literature and science, and vigorously promote the application of new technologies represented by digital technology and information technology, promote foreign language interdisciplinary research, and strive to build interdisciplinary teaching team and scientific research team. The sustainable development of talent training needs to be optimized and innovated from different levels such as training concept, curriculum system design, curriculum development, learning resources, teaching informatization, learning standards and teacher professional development. The process of talent training needs to be guided by the long-term development of students, and insist on continuous improvement in the process of teaching practice, so as to continuously improve the ability and quality of foreign language talent training.

\section{Acknowledgments}

This paper is funded by the key Project of Hubei Provincial Educational Science Planning "Research on the Construction and Application of Online Corpus for Academic English Learners" (2020ZA13).

\section{References}

Chen, P. (2019). What kind of talents should the "new liberal arts" cultivate. Guangming Daily. Retrieved from https://m.cnwest.com/tianxia/a/2019/05/20/17795329.html

Fan, L. M. (2020). "New liberal arts": the needs of the times and the focus of construction. Chinese University Teaching, (5), 4-8. https://doi.org/10.3969/j.issn.1005-0450.2020.05.002

Guo, Y. J. (2021). New liberal arts and the construction of foreign language majors. Contemporary Foreign Language Studies, (3), 29-34+113. http://chinadoi.cn/10.3969/j.issn.1674-8921.2021.03.003

Liu Jianjun. (2021). New Liberal Arts, and the Construction of Foreign Language Programs. Contemporary Foreign Languages Studies, 453(3), 29-34. https://doi.org/10.3969/j.issn.1674-8921.2021.03.003

$\mathrm{Hu}, \mathrm{K}$. B. (2020). The construction and development of foreign language disciplines from the perspective of new liberal arts-ideas and paths. Foreign Languages in China, 17(3), 14-19. Retrieved from https://d.wanfangdata.com.cn/periodical/ChlQZXJpb2RpY2FsQ0hJTmV3UzIwMjExMjMwEhF6aG9uZ2d 3eTIwMjAwMzAwMxoIYWlrZ3VnYWQ\%3D

Huang, Q. B., \& Tian, X. M. (2020). The source, characteristics and construction path of "new liberal arts". Journal of Soochow University: Education Science Edition, 8(2), 75-83. https://doi.org/10.19563/j.cnki.sdjk.2020.02.007

Jiang, H. C. (2007). An analysis of the connotation of university disciplinary culture. Jiangsu Higher Education, (3), 26-29. https://doi.org/10.13236/j.cnki.jshe.2007.03.008

Jiang, H. X. (2018). Reflections on English education in the new era. Foreign Language Education, 39(2), 49-51+67. https://doi.org/10.16362/j.cnki.cn61-1023/h.2018.02.010

Lai, W. B., Mao, Y. N., Wen, X. P., \& Zhang, Y. J. (2009). A preliminary exploration of interdisciplinary integrated teaching for English majors. Journal of Liaoning Institute of Education Administration, 26(9), 111-113. Retrieved

from https://kns.cnki.net $/ \mathrm{kcms} /$ detail/detail.aspx?dbcode=CJFD\&dbname $=$ CJFD2009\&filename $=$ LJXY2009090 41\&uniplatform=NZKPT\&v=rvDFcvutUH9h-yDX-9g_DKQoWe-EcDtxkZOhDSvRbt0zX8K70V8BNvop $5 \mathrm{cInIsHr}$

Li, M. Q. (2012). Research on the teaching practice of ESP interdisciplinary foreign language talent training - taking the course of "Aquaculture English" as an example. Journal of Hebei University of Technology (Social Science Edition), 4(2), 29-33. https://doi.org/10.14081/j.cnki.cn13-1396/g4.2012.02.004 
Li, P. N. (2017). What is the real interdisciplinary integration—from a few cases. People's Education, (11), 76-80. Retrieved from https://kns.cnki.net $/ \mathrm{kcms} /$ detail $/$ detail.aspx ?dbcode $=$ CJFD\&dbname $=$ CJFDLAST2017\&filename $=$ RMJY20 1711026\&uniplatform=NZKPT\&v=nSEhATgw3Ri7Xnbs2iTRaiKsPRFj9LdSkrRNrnTlvu6WDBu3F6mx2 MZJ9DLWuXMQ

Lori Varlotta. (2018). Designing and implementing systemic academic change---Hiram College's model for the new liberal arts. Planning for Higher Education Journal, 47(1), 1-20. Retrieved from https://www.hiram.edu/wp-content/uploads/2018/12/Designing-and-Implementing-Systemic-Academic-Cha nge-1.pdf

Ma, X., Li, X., \& Sun, X. D. (2021). New liberal arts construction: bottleneck problems and solutions. China University Teaching, (Z1), 21-25+34. $\quad$ Retrieved from https://kns.cnki.net $/ \mathrm{kcms} /$ detail $/$ detail.aspx $?$ dbcode $=$ CJFD\&dbname $=$ CJFDLAST2021\&filename $=J X C Y 20$ 21Z1006\&uniplatform=NZKPT\&v=9bRrWZYQ0tFgnek34IFmPVdtBUVeQbdLeHdYPR8jnX16ah-tWWN AhQLYTBCj3QSR

Qiu, S. G. (2004). Reflections on University Interdisciplinary Education. Journal of Hebei Normal University (Educational Science Edition), 6(1), 78-82. https://doi.org//10.3969/j.issn.1009-413X.2004.01.015

Sun, J. H. (2012). Research on interdisciplinary design in the field of foreign language education. Journal of Liaoning Normal University (Social Science Edition), 35(5), 634-637. https://doi.org/10.3969/j.issn.1000-1751.2012.05.013

Sun, M. J. (2018). Research on the talent training model of foreign language subjects in colleges and universities from an interdisciplinary perspective. Crazy English PRO, (3), 53-55. Retrieved from https://d.wanfangdata.com.cn/periodical/fkyy-j201803019

Wang, J. J. (2021). What does the construction of new liberal arts mean for foreign language majors? Foreign Languages in China, 18(1), 1+24. https://doi.org/10.13564/j.cnki.issn.1672-9382.2021.01.001

Wang, Z. (2018). From simple compounding to interdisciplinary foreign language talent cultivation: On the cultivation of English majors in the context of the new era. Shandong Foreign Language Teaching, 39(3), 61-69. https://doi.org/10.16482/j.sdwy37-1026.2018-03-007

Wang, Z. K. (2019). New liberal arts: a feast of discipline integration. Chinese Journal of Science, 2019-05-08(01). Retrieved from https://news.sciencenet.cn/htmlnews/2019/5/425983.shtm

Wu, Y. (2019). New mission, big pattern, new liberal arts, big foreign language. Foreign Language Education in China, 2(2), 3-7+90. Retrieved from https://kns.cnki.net/kcms/detail/detail.aspx?dbcode=CJFD\&dbname=CJFDLAST2019\&filename=WYQY2 01902001\&uniplatform=NZKPT\&v=cWKj1b7ZXA0qc3ROMTUHMgU55vGtAYBOVFjhM-th8x4pFrTGj O08XRg3fjaIPhIA

$\mathrm{Xu}, \mathrm{X}$. M. (2019). The new era of higher education and the cultivation of outstanding legal talents. China University Teaching, (10), 7-11. Retrieved from https://kns.cnki.net $/ \mathrm{kcms} /$ detail $/$ detail.aspx $?$ dbcode $=$ CJFD \&dbname $=$ CJFDLAST2020\&filename $=J X C Y 20$ 1910002\&uniplatform=NZKPT\&v=XiWq8B-JfEf0-WfdWkrd_rBkQX4_MzY0O9fA-UthcBJPuesmG_fLH a321F8zGwxP

Yang, F. (2019). National awareness, interdisciplinary spirit and application concept of higher foreign language education. Contemporary Foreign Language Studies, (2), 1-2. Retrieved from https://d.wanfangdata.com.cn/periodical/kjyyxx201902001

Zha, M. J. (2017). The humanities attributes of English majors and the significance of humanities courses - focusing on the humanities courses of "National Standard". Foreign Languages and Cultures, 1(1), 18-26. https://kns.cnki.net/kcms/detail/detail.aspx?dbcode=CJFD\&dbname=CJFDLAST2018\&filename=WYWH2 01701004\&uniplatform=NZKPT\&v=sdSArM5iJi2vkhvh4KXsMqscQfnawaobYcd1OFSlqXF3LW9VGNY L52jHxmvhKwwe

Zhang, S. L., \& Chen, S. Y. (2011). Discussion on several issues in the positioning of foreign languages in colleges and universities. China Adult Education, (17), 143-145. Retrieved from https://kns.cnki.net/kcms/detail/detail.aspx?dbcode=CJFD\&dbname=CJFD2011\&filename=ZCRY2011170 
61\&uniplatform=NZKPT\&v=xzZc0IApOctRoXA8dOfQafauUjRmU6Fmi6ahW6yJBwM9pt6pl-d_T_2Xfe 1T9xss

\section{Notes}

Note 1. The pilot enrollment reform of basic disciplines, also known as the Strong Foundation Program, is an enrollment reform work carried out by the Ministry of Education, mainly to select and cultivate students who are interested in serving major national strategic needs and have excellent overall quality or top-notch basic disciplines.

Note 2. On April 29, 2019, the Ministry of Education's "Six Excellence and One Top-notch" plan 2.0 startup meeting was held at Tianjin University. At the meeting, the "National New Engineering Education Innovation Center" established by the Ministry of Education and supported by Tianjin University was officially unveiled. The plan includes the Education and Training Program for Excellent Engineers 2.0, the Education and Training Program for Excellent Doctors 2.0, the Education and Training Program for Excellent Agriculture and Forestry Talents 2.0, the Training Program for Excellent Teachers 2.0, the Education and Training Program for Excellent Legal Talents 2.0, the Education and Training Program for Excellent Journalism and Communication Talents 2.0, and the Basic Discipline Top-notch student training program 2.0.

\section{Copyrights}

Copyright for this article is retained by the author(s), with first publication rights granted to the journal.

This is an open-access article distributed under the terms and conditions of the Creative Commons Attribution license (http://creativecommons.org/licenses/by/4.0/). 